\title{
An assessment of the utilization of diagnostic parasitology laboratory services in Ontario
}

\author{
Harold Richardson bSc MD frCPC, Christine Fleming ba mLt, Josephine PALMER art, ERLUo Chen, \\ ROBERT LANNIGAN MD FRCPC AND THE MICROBIOLOGY COMMITTEE
}

H RICHARDSON, C FLEMING, J PALMER, E CHEN, R LANNIGAN AND THE MICROBIOLOGY COMMITTEE. An assessment of the utilization of diagnostic parasitology laboratory services in Ontario. Can J Infect Dis $1996 ; 7(4): 237-242$.

OBJECTIVE: Diagnostic parasitology services in Ontario were assessed to determine whether the reduction in the number of provider laboratories from 209 to 70 over the period 1977 to 1994 has affected the availability and quality of service.

DESIGN: A questionnaire on parasitology practice was distributed to all laboratories. Responses were validated against data from the requisitions, work cards and reports submitted by licensed parasitology laboratories in a pattern-ofpractice survey.

SETTING AND PARTICIPANTS: Laboratories in Ontario are licensed by the provincial Ministry of Health and subjected to mandatory proficiency testing. Laboratories not licensed in parasitology may receive specimens for referral to another facility for processing.

MAIN OUTCOME MEASURES: Assessment included receipt of fecal specimens for parasitology, on-site testing, the limitation of testing, work referred elsewhere for primary investigation or confirmation, laboratory to which work was referred, and the turnaround time for both on-site and referred work.

RESULTS: Ninety-eight per cent of 338 laboratories returned the questionnaire. Three hundred and six received specimens for parasitology. Sixty-four performed the testing. Of the remainder, 235 referred to 40 laboratories. Approximately 31,000 specimens were processed monthly, with $78 \%$ examined within private laboratories and $62 \%$ having a turnaround time of at least three days. The yield of positive findings was $3 \%$ or more of patients.

CONCLUSIONS: The presence of fecal parasites has been reliably determined and the genus, species and stage of the organism correctly identified. Utilization must be improved through understanding of the factors increasing the pretest likelihood of a positive finding.

Key Words: Laboratory, Parasitology, Proficiency testing, Quality management, Utilization

\section{Évaluation de l'utilisation des services de laboratoire de parasitologie diagnostique en Ontario}

OBJECTIF : Des services de parasitologie diagnostique en Ontario ont été évalués afin de déterminer si la réduction du nombre de laboratoires fournisseurs, qui est passé de 209 à 70 au cours de la période allant de 1977 à 1994, a affecté l'accessibilité et la qualité de ce type de service.

voir page suivante

Members of the Microbiology Committee: Robert Lannigan MD FRCPC, Jane Gun-Munro MLT FIMLS FCSLT, Donald E Low MD FRCPC, Josephine Palmer MLT ART, Donna Thompson MSc MLT

Laboratory Proficiency Testing Program and the Institute for Clinical Evaluative Sciences, Toronto, Ontario

Correspondence and reprints: Dr Harold Richardson, Director, Laboratory Proficiency Testing Program, Suite 501, 250 Bloor Street East, Toronto, Ontario M4W 1E6. Telephone 416-323-9540 ext 242, fax 416-323-9324, e-mail richardson@lptp.on.ca

Received for publication December 12, 1995. Accepted February 29, 1996 
MODÈLE : Un questionnaire sur les pratiques en parasitologie a été distribué à tous les laboratoires. Les réponses ont été validées par comparaison avec des données provenant de formules de demande, de fiches de travail et de rapports soumis par des laboratoires de parasitologie autorisés dans le cadre d'un sondage sur les habitudes de pratique.

CONTEXTE ET PARTICIPANTS : Des laboratoires ontariens obtiennent du ministère provincial de la santé l'autorisation de pratiquer et sont soumis à des tests de compétence obligatoires. Les laboratoires non autorisés à pratiquer des analyses parasitologiques peuvent recevoir des spécimens en vue de les acheminer à un autre laboratoire pour traitement.

PRINCIPALES MESURES PARAMÉTRIQUES : L'évaluation portait entre autre sur la réception de spécimens de selles pour analyse parasitologique, analyse sur place, limites de l'analyse, travaux adressés ailleurs pour investigation primaire ou confirmation, laboratoire auquel le travail a été adressé et délai d'obtention du travail effectué sur place et du travail effectué en sous-traitance.

RÉSULTATS : Quatre-vingt-dix-huit pour cent des 338 laboratoires ont retourné le questionnaire. Trois cent six ont reçu des spécimens pour parasitologie. Soixante-quatre ont effectué l'analyse. Parmi les laboratoires restants, 235 ont adressé leurs analyses à 40 laboratoires. Environ 31000 spécimens ont été traités tous les mois, $78 \%$ ayant été examinés dans des laboratoires privés et $62 \%$ ayant obtenu un délai d'au moins trois jours. La production de résultats positifs a été de $3 \%$ ou plus des patients.

CONCLUSIONS : La présence de parasites dans les selles a été identifiée de façon fiable et le genre, l'espèce et le stade de développement de l'organisme a été correctement identifié. L'utilisation doit être améliorée grâce à une compréhension des facteurs qui augmentent la probabilité d'un résultat positif avant même l'analyse.

$\mathrm{C}$ linical laboratories in Ontario are licensed by the provincial Ministry of Health and are required to participate in external quality assessment by the Laboratory Proficiency Testing Program (LPTP). In 1977, LPTP began testing laboratories that examine samples for gastrointestinal parasites. Four surveys, each containing four samples, were distributed each year to these laboratories. The required standard of performance was to determine the presence or absence of parasites and to identify correctly the genus, species and stage of any parasite present. In the beginning, a large percentage of laboratories failed to reach the expected level of performance. Over time there was a remarkable improvement due to the LPTP strategy of educational support for the poor performers and a combination of the voluntary withdrawal from testing by many laboratories and the improved performance of the remainder (1). Between 1977 and 1994 the number of laboratories licensed in parasitology fell from 209 to 70 . A reduction of this magnitude caused concern regarding access to diagnostic parasitology services in the province. A questionnaire survey submitted to all laboratories, a pattern-of-practice survey of parasitology laboratories and a review of gastrointestinal parasites reported in Ontario were used to assess the availability and quality of the current service.

\section{MATERIALS AND METHODS}

Questionnaire survey: A questionnaire was sent to all 338 licensed laboratories in Ontario in January 1995. Information requested included whether the laboratory received fecal specimens for gastrointestinal parasites, whether testing was carried out on-site, the nature and extent of work referred elsewhere for either primary investigation or confirmation, the name of the laboratory to which such work is referred, and the turnaround time (TAT) for both on-site and referred work. Return of the completed questionnaire was either by facsimile or by mail. Each laboratory was identified by its unique LPTP number. Data were captured by keyboard entry and analyzed using the LPTP Ingres relational database management system (Computer Associates, New York). Geographic location and other demographic information was available from the LPTP database.

Pattern-of-practice survey: In December 1994, a pattern-ofpractice survey required all licensed parasitology laboratories to submit copies of the test requisitions, work cards and reports on the last $10 \mathrm{fecal}$ specimens reported as positive for any parasites. Laboratories were also asked to submit the last 10 reports of specimens that were referred to another laboratory for a second opinion.

The requisitions, work cards and reports were reviewed by the LPTP microbiology consultant technologist and a consultant in parasitology. External benchmark criteria were used to the extent that these were available (2). Data were compared with the self-reported information provided by these laboratories on the questionnaire survey. Information was derived to show length of time to produce 10 positive reports, presence and type of clinical information provided with the test requisition, routine methods used in the laboratory, average TAT for routine examinations, average TAT for referred specimens, reporting formats in use, incidence and variety of species identified, and species of parasites referred for a second opinion.

Definitions: TAT is defined as the time from the collection of the specimen to the time of issuance of the final report to the requesting physician; a referral laboratory is one that receives specimens from another laboratory for primary examination; a referring laboratory is one that sends specimens to another laboratory for testing; and a reference laboratory is one that receives specimens or other materials from a referring laboratory for confirmation, a second opinion or for quality control purposes.

\section{RESULTS}

Of 338 licensed and active laboratories, 334 (98.8\%) returned the completed questionnaire, and the data were included in the analysis. Of the 334, 306 received fecal specimens for parasitological examination but only 68 performed testing on-site. Of the remaining 238 laboratories, 235 
TABLE 1

Turnaround times associated workload - self-reported data

\begin{tabular}{|c|c|c|c|c|c|c|}
\hline \multirow{2}{*}{$\begin{array}{l}\text { Workload } \\
\text { (n/month) }\end{array}$} & \multirow{2}{*}{$\begin{array}{c}\% \text { of labs } \\
\left(n=66^{*}\right)\end{array}$} & \multicolumn{5}{|c|}{ Turnaround time (days) } \\
\hline & & $1-3$ & $4-7$ & 8-14 & $15-21$ & $>21$ \\
\hline $10-49$ & 20.0 & 31.0 & 38.0 & 31.0 & 0 & 0 \\
\hline $50-99$ & 18.0 & 50.0 & 42.0 & 0 & 8.0 & 0 \\
\hline 100-199 & 18.0 & 25.0 & 50.0 & 17.0 & 8.0 & 0 \\
\hline 200-299 & 12.0 & 12.5 & 62.5 & 12.5 & 12.5 & 0 \\
\hline $300-399$ & 4.5 & 33.3 & 33.3 & 33.3 & 0 & 0 \\
\hline $400-499$ & 4.5 & 67.0 & 0 & 33.0 & 0 & 0 \\
\hline $500-999$ & 11.0 & 71.0 & 29.0 & 0 & 0 & 0 \\
\hline 1000-1999 & 4.5 & 100.0 & 0 & 0 & 0 & 0 \\
\hline 2000-2999 & 3.0 & 50.0 & 50.0 & 0 & 0 & 0 \\
\hline 3000-3999 & 3.0 & 50.0 & 50.0 & 0 & 0 & 0 \\
\hline$\geq 4000$ & 1.5 & 100.0 & 0 & 0 & 0 & 0 \\
\hline
\end{tabular}

*Two laboratories did not provide workload information

named the laboratory to which specimens were referred for primary examination.

Referral pattern: There were 40 referral laboratories. Thirteen were hospital laboratories processing work from 16 other hospital laboratories. Eight of these 13 providers also processed out-patient specimens on behalf of the Hospital In-common Laboratory. Fifteen private laboratories acted as the referral centres for 69 other private sector facilities and two hospital laboratories. Twelve facilities of the Ontario Public Health Laboratory Services Branch processed specimens from 144 hospital and three private sector laboratories.

The ratio of laboratories that received specimens for intestinal parasitology to the number of referral laboratories in the region was highest in the northwest at 19:1 and lowest in central east and eastern Ontario, at 6.6 and 6.9, respectively. The ratios for northeast, southwest and central west were $8.5,8.8$ and 9.8, respectively.

Workload: Approximately 31,000 fecal specimens were examined for parasites province-wide each month, of which 24,270 $(78 \%)$ were examined within the private laboratory sector. Government-operated laboratories processed 3610 and hospital laboratories 3342 specimens. Six private sector laboratories processed more specimens per month $(17,700)$ than the other 62 laboratories collectively $(13,522)$. The average number of specimens examined by an individual facility varied from 13 to 4500 .

TAT: Self-reported information in the questionnaire indicated that over $90 \%$ of fecal specimens had a TAT of at least seven days, with approximately $62 \%$ at least three days. Comparison of this information with the actual TAT calculated from the pattern-of-practice survey showed that laboratories tended to underestimate the actual TAT; only $30 \%$ of laboratories achieved a three-day TAT, 39\% reported between four and seven days and $31 \%$ between eight and 14 days.

The TAT appeared to be inversely related to workload, as shown in Table 1. Fifteen laboratories processing between 500 and 4000 or more specimens per month issued all reports in seven or more days, whereas the 51 laboratories processing
TABLE 2

Turnaround times (TAT) reported by referring laboratories $(n=227)$ by type of referral laboratory

\begin{tabular}{|c|c|c|c|}
\hline \multirow[b]{2}{*}{ TAT (days) } & \multicolumn{3}{|c|}{ Type of referral laboratory } \\
\hline & $\begin{array}{l}\text { Hospital } \\
n=16(\%)\end{array}$ & $\begin{array}{c}\text { Private } \\
n=68(\%)\end{array}$ & $\begin{array}{c}\text { Government } \\
n=143(\%)\end{array}$ \\
\hline $1-3$ & 6.0 & 57.0 & 0 \\
\hline $4-7$ & 44.0 & 37.0 & 15.0 \\
\hline 8-14 & 50.0 & 4.0 & 50.0 \\
\hline $15-21$ & 0 & 1.0 & 29.0 \\
\hline$>21$ & 0 & 0 & 6.0 \\
\hline
\end{tabular}

TABLE 3

Turnaround time (TAT) for referred specimens, by region, using data provided by referring laboratories $(n=224) *$

TAT (days) reported by referring laboratories (\% of laboratories)

\begin{tabular}{lrrrrc} 
Region & $\mathbf{1 - 3}$ & $\mathbf{4 - 7}$ & $\mathbf{8 - 1 4}$ & $\mathbf{1 5 - 2 1}$ & $\mathbf{> 2 1}$ \\
\hline Southwest & 17.0 & 17.0 & 46.0 & 11.0 & 9.0 \\
Central west & 15.0 & 30.0 & 30.0 & 20.0 & 5.0 \\
Central east & 32.0 & 28.0 & 29.0 & 11.0 & 0 \\
East & 11.0 & 19.0 & 44.0 & 19.0 & 6.0 \\
Northeast & 7.0 & 27.0 & 40.0 & 23.0 & 3.0 \\
Northwest & 6.0 & 11.0 & 33.0 & 44.0 & 6.0 \\
\hline
\end{tabular}

*Eight laboratories did not provide TAT

between 10 and 499 stool samples per month issued only $74 \%$ of reports within this time.

Specimens referred from the receiving laboratory for primary examination had a much longer TAT. Only 93 of 227 referring laboratories experienced a TAT of seven or more days, whereas 54 of 68 referral laboratories reached this target. Fifty-one of 227 referring laboratories had a TAT of 15 or more days. As shown in Table 2, TAT for specimens referred to private laboratories was considerably shorter than for those specimens referred to hospital or public health laboratories.

The northwest region of the province had the longest TAT, as illustrated in Table 3 . This region had the highest ratio of referring to referral laboratories and the greatest distances between laboratories.

Utility of the requisition: Clinical history, travel history or reason for the requested examination was given on only 155 (23.1\%) of 672 requisitions submitted during the pattern-ofpractice survey. More than $75 \%$ of fecal specimens found by laboratories to be positive for parasites were submitted without the necessary clinical information to enable the laboratory to assess its findings adequately. Many forms did not have a space to allow the clinician to provide the information. Others, as shown in Table 4, contained information that was not relevant to the test required.

Time required to produce 10 positive reports: As part of the pattern-of-practice survey, data from 672 fecal specimens were received from 69 laboratories. Almost half of the laboratories licensed to perform intestinal parasitological analysis actually 
TABLE 4

Types of clinical information provided by physician

\begin{tabular}{lcr}
\hline Clinical information & $\begin{array}{c}\text { Number of specimens } \\
(\mathbf{n}=\mathbf{1 5 5})\end{array}$ & \% \\
\hline Diarrhea & 40 & 25.8 \\
Abdominal pain & 12 & 7.7 \\
Travel & 12 & 7.7 \\
Post-treatment & 11 & 7.1 \\
Nausea & 9 & 5.8 \\
Passed worm & 7 & 4.5 \\
Dehydration & 5 & 3.2 \\
Fever & 5 & 3.2 \\
Contact & 4 & 2.6 \\
HIV-positive & 4 & 2.6 \\
Bloody stools & 3 & 1.9 \\
Gastrointestinal bleeding & 3 & 1.9 \\
Colitis & 2 & 1.3 \\
Other & 16 & 10.3 \\
\hline
\end{tabular}

HIV Human immunodeficiency virus

saw very little positive material in the routine specimens they received; $29 \%$ were able to produce 10 positive reports within the week before date requested, $23.2 \%$ within one month, $27.5 \%$ within six months and $8.7 \%$ within one year, while $7.3 \%$ of laboratories had to go back more than one year. One laboratory was able to submit only five positive reports from the preceding two years. It was not possible to determine dates from $4.3 \%$ of the submissions.

Laboratory methods: According to the work cards submitted, $62.3 \%$ of 68 laboratories routinely performed an examination of both a concentrate and a permanent stained smear on all specimens received. In addition, $26.1 \%$ of participants performed another examination usually for Cryptosporidium parvum. In contrast $2.9 \%$ of laboratories performed only a direct wet mount and no other examination unless this preparation was positive. The methods used could not be determined for $14.8 \%$ of participants either because the information was not on the work cards or because the cards were not submitted for review.

Organisms reported: In total, 957 parasites were reported on the 672 reports submitted. Organisms reported are listed in Table 5 in order of frequency. Seven laboratories reported only a single organism, and the majority were Blastocystis hominis. The largest number of different species found in a single specimen was 10. A total of 14 different species of protozoa and 10 different species of helminths were reported. Of these, the following were regularly referred to another laboratory for confirmation or a second opinion: Entamoeba histolytica, Giardia lamblia, Dientamoeba fragilis, Endolimax nana, Entamoeba polecki, C parvum, hookworm and Strongyloides stercoralis. Only 27 laboratories submitted evidence of referral for a second opinion. Of those submitted, $26 \%$ were reported back to the referring laboratory within one week, $59.2 \%$ within two weeks and $14.8 \%$ after more than two weeks.

Reporting practices: Most laboratories reported full names of
TABLE 5

Incidence of parasite species reported

\begin{tabular}{|c|c|c|}
\hline & $\begin{array}{l}\text { Number reported } \\
\quad(\mathbf{n}=957)\end{array}$ & $\%$ \\
\hline \multicolumn{3}{|l|}{ Protozoa } \\
\hline Dientamoeba fragilis* & 182 & 27.1 \\
\hline Endolimax nana* & 163 & 24.3 \\
\hline Entamoeba coli & 129 & 19.2 \\
\hline Giardia lamblia* & 125 & 18.6 \\
\hline Blastocystis hominis & 103 & 15.3 \\
\hline Entamoeba hartmanni & 63 & 9.4 \\
\hline Entamoeba histolytica* & 32 & 4.8 \\
\hline Cryptosporidium parvum* & 27 & 4.0 \\
\hline lodamoeba bütschlii & 20 & 3.0 \\
\hline Chilomastix mesnili & 20 & 3.0 \\
\hline Enteromonas hominis & 5 & 0.7 \\
\hline Trichomonas hominis & 4 & 0.6 \\
\hline $\begin{array}{l}\text { Possible Microsporidium } \\
\text { species }\end{array}$ & 2 & 0.3 \\
\hline Entamoeba polecki* & 1 & 0.1 \\
\hline \multicolumn{3}{|l|}{ Helminth ova } \\
\hline Trichuris trichiura & 29 & 4.2 \\
\hline Hymenolepis nana & 11 & 1.6 \\
\hline Hookworm species* & 9 & 1.3 \\
\hline Enterobius vermicularis & 9 & 1.3 \\
\hline Ascaris lumbricoides & 7 & 1.0 \\
\hline Diphyllobothrium species & 5 & 0.7 \\
\hline Clonorchis sinensis & 4 & 0.6 \\
\hline Taenia species & 3 & 0.4 \\
\hline Strongyloides stercoralis* & 2 & 0.3 \\
\hline Schistosoma mansoni & 2 & 0.3 \\
\hline
\end{tabular}

*Species of parasites sent by one or more laboratories to a reference laboratory for confirmation

all parasites found and their stages. Only one laboratory reported the presence of parasites without naming them. Three laboratories reported the quantity of protozoa found. The format of the reports varied greatly, and many used 'canned messages' on computer-generated reports to explain the clinical significance of the findings.

\section{DISCUSSION}

Most laboratories providing diagnostic gastrointestinal parasitology services reliably determined the presence of parasites and correctly identified the genus, species and stage of the organism (1), but only $40 \%$ of the original laboratories that offered this service in 1977 continue in operation. Continuing consolidation and regionalization of laboratory services have the potential to leave large areas of the province underserviced, particularly in the less densely populated regions, and to accentuate the existing differences in the quality of service provided by private sector, hospital and public health laboratories.

Noteworthy are the differences in TAT in the service provided by the different laboratory sectors. A total of 147 refer- 
ring laboratories were serviced directly by the government through the central and regional public health laboratories. These laboratories examined $15 \%$ of the total workload and had TATs of eight or more days for $85 \%$ of the work. In contrast, the private sector had 15 laboratories serving as referral centres for 71 other laboratories, processed more than $70 \%$ of the provincial workload and reported on $57 \%$ of its specimens within three days and on $94 \%$ within seven days. The efficiency of the specimen courier services and the use of electronic reporting were likely significant contributors to the rapid TAT of the private sector. Laboratories acting as referral centres tended to underestimate their actual TAT for primary examination. Even so, they reported on specimens received directly in the laboratory between seven and 14 days sooner than they did on specimens referred to them by another laboratory. The clinically desirable TAT for intestinal parasitology has yet to be determined. It has been suggested that there is rarely any urgency for the examination when specimens are preserved during collection (1). While this claim may be true in terms of the integrity of the specimen it shows a lack of sensitivity to the investigation and management needs of the referring health professionals and to the physical and mental health needs of the patient. LPTP has recommended to all laboratories licensed for parasitological analysis that the ideal TAT for routine parasitological examination should be within $72 \mathrm{~h}$ of receipt. Priority or 'STAT' testing should take precedence over routine testing and should be reported within $24 \mathrm{~h}$.

Material sent to a reference facility usually is associated with a longer TAT than specimens referred for primary examination, and this is to be expected given that special methods may be necessary. LPTP recommends that laboratories have a written protocol for referral of specimens for confirmation, second opinion or quality control purposes; that reference laboratories be provided with full clinical and travel history in addition to the reasons for the referral; that the referring laboratory issue an interim report to the physician indicating provisional results; and that referring laboratories track all specimens or materials submitted to another laboratory for further examination.

With increasing cost constraints, there is a need for optimal utilization of laboratory services. In Ontario over 31,000 fecal specimens are examined for intestinal parasites each month. At present, the cost per test performed in hospital laboratories cannot be determined from the available database. Tests performed in private sector laboratories are billed according to the schedule of benefits of the Ministry of Health at an average cost of $\$ 45.15$ per specimen. Since the positivity rate for any parasite or other significant finding is of the order of $3 \%$ to $5 \%$ when corrected for multiple specimens from the same patient, and most of these are nonpathogenic protozoans, there appears to be opportunity for improved utilization. There is a lack of necessary clinical information on more than $75 \%$ of requisitions. The overall low yield of pathogenic organisms did not allow a meaningful comparison of the positivity rate of specimens with and without accompanying clinical information. Nonetheless, LPTP considers such information valuable and recommends that the requisition form must provide sufficient space to allow documentation of the travel history of the patient. Details of any therapy that may interfere with the laboratory diagnosis, such as mineral oil, barium, antibiotics, antimalarials and nonabsorbable antidiarrheal preparations (2), must be provided. The precise value of screening for parasitic disease is hard to quantify because the chance of finding an important treatable illness depends on the level of risk of infection to which that individual has been exposed (3). Research into factors that increase the pretest likelihood of a positive finding is required. A better understanding by requesting physicians of the benefits of providing essential clinical information and of the indications for submitting specimens for parasitological analysis would likely improve utilization.

Over half of the laboratories see very little positive material in the specimens they receive. It is likely that the technologists in these facilities have difficulty in maintaining competence since the mainstay of diagnostic parasitology is, and is likely to remain, the microscopic morphology of stained smears of the stool specimen and its concentrate. LPTP participants requiring more than six months to generate 10 positive reports usually find $\mathrm{G}$ lamblia or $\mathrm{E}$ nana, in contrast to the range of parasites reported by busier laboratories. The ability to maintain expertise is related to the volume of material processed and the incidence of positive findings, as was shown in a comparative study of 2000 parasitological specimens (4). The rate of detection of positives by technologists working only in parasitology was twice that of general microbiologists who were also performing other laboratory work. The newer diagnostic approaches (5-9), including molecular diagnostics $(10,11)$, that are under development may alleviate some of the demand for morphological expertise. Meanwhile, laboratories should review regularly the records of the number of specimens examined, number of positive reports and number of parasites found. LPTP recommends that those with limited exposure to positive specimens either withdraw from service or provide for the continuing education and competency of staff. Laboratories with fewer than 10 positive specimens in six months should refer all positive and a reasonable number $(10 \%)$ of negative clinical specimens for a second opinion. Conversely, in high volume laboratories, technologists may be assigned more than the recommended number of specimens and may not have the necessary time available to report adequately. LPTP advises that a reasonable workload for an experienced technologist is 15 specimens per day when both a stained smear and a fecal concentrate are examined, and that a trained but inexperienced person can be expected to handle 10 samples per day.

Virtually all laboratories routinely examine both a concentrate and a permanent stained smear on all specimens received. The LPTP minimum standard includes an appropriate concentration technique for helminths and protozoan cysts, a permanent staining procedure for protozoan trophozoites and a method for the detection of intestinal coccidians, when required.

Most Ontario laboratories report the full name of any para- 
site found and its stages. LPTP recommends this practice regardless of the current status of its potential pathogenicity. A minority report the quantity of protozoa found. This is not considered acceptable practice: it has the potential to be misleading because protozoa multiply and numbers of organisms present at any given time do not reflect clinical significance. Certain species of helminths and nonparasitic findings, such as red blood cells, white blood cells and yeasts, should be quantified.

The frequency of reporting of different parasite species was derived from sequential positive reports issued by participating laboratories to requesting physicians and illustrates current Ontario practice. There is no established standard of

\section{REFERENCES}

1. Wood DE, Palmer J, Missett P, Whitby JL. Proficiency testing in parasitology: an educational tool to improve laboratory performance. Am J Clin Pathol 1994;102:490-4.

2. NCCLS Proposed Guidelines M28-P. Procedures for the Recovery and Identification of Parasites from the Intestinal Tract. Villanova: National Committee for Clinical Laboratory Standards, 1993.

3. Churchill DR, Chiodini PL, McAdam KP. Screening the returned traveller. Br Med Bull 1993;49:465-74

4. Mohr E, Mohr I. Statistical analysis of the incidence of positives in the examination of parasitological specimens. J Clin Microbiol 1992;30:1572-4.

5. Kehl KS, Cicirello H, Havens PL. Comparison of four different methods for detection of Cryptosporidium species. J Clin Microbiol 1995;33:416-8.

6. Favennec L, Egraz-Bernard M, Comby E, Lemetell D, Ballet JJ, practice, and LPTP is developing guidelines on the reporting of pathogenic, nonproven pathogenic and nonpathogenic parasites. Meanwhile it is likely that the reporting of nonproven pathogens, such as B hominis, will vary among laboratories.

The pattern-of-practice survey and questionnaire concerning examination of fecal specimens have provided valuable information on the current state of diagnostic parasitology in Ontario. The information derived confirms and expands on the findings of the parasitology challenge surveys, and has allowed the development of specific quality improvement strategies and recommendations. Continuing use of these external quality assessment instruments is anticipated.

Brasseur P. Immunofluorescence detection of Cryptosporidium parvum in Caco-2 cells: a new screening method for anticryptosporidial agents. J Eukaryot Microbiol 1994;41:39S.

7. Sherwin T, Read M. Immunofluorescence of parasites. Methods Mol Biol 1993;21:407-14.

8. Hunt PD, Hall R. Immunoblotting and enzyme-linked immunosorbent assay. Methods Mol Biol 1993;21:397-406.

9. Chan FT, Guan MX, Mackenzie AM. Application of indirect immunofluorescence to detection of Dientamoeba fragilis trophozoites in fecal specimens. J Clin Microbiol 1993;31:1710-4.

10. Piarroux R, Gambarelli F, Dumon H, et al. Comparison of PCR with direct examination of bone marrow aspiration, myeloculture, and serology for diagnosis of visceral leishmaniasis in immunocompromised patients. J Clin Microbiol 1994;32:746-9.

11. Weiss JB. DNA probes and PCR for diagnosis of parasitic infections. Clin Microbiol Rev 1995;8:113-30. 


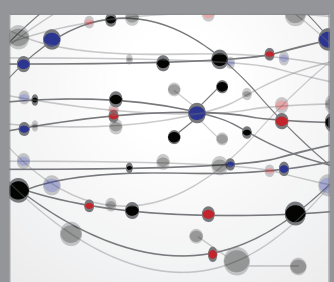

The Scientific World Journal
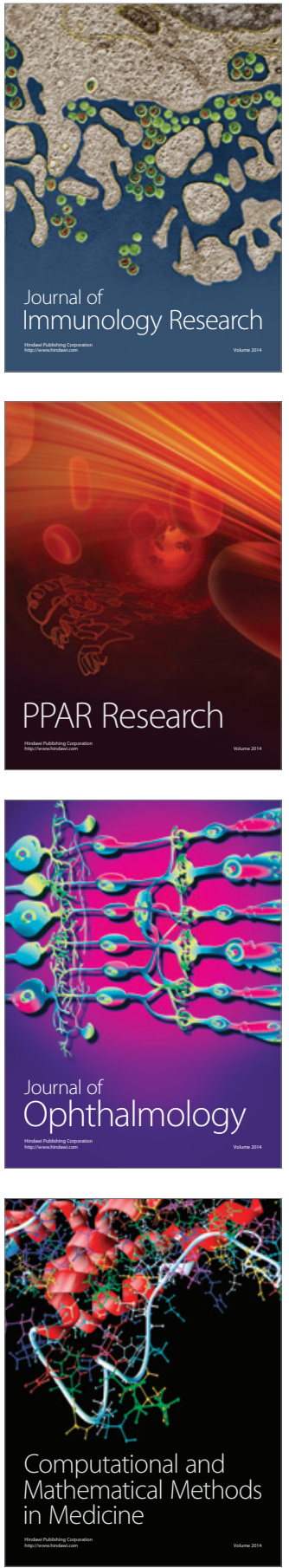

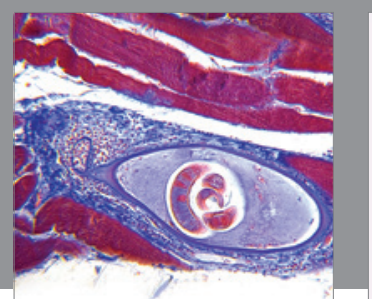

Gastroenterology Research and Practice

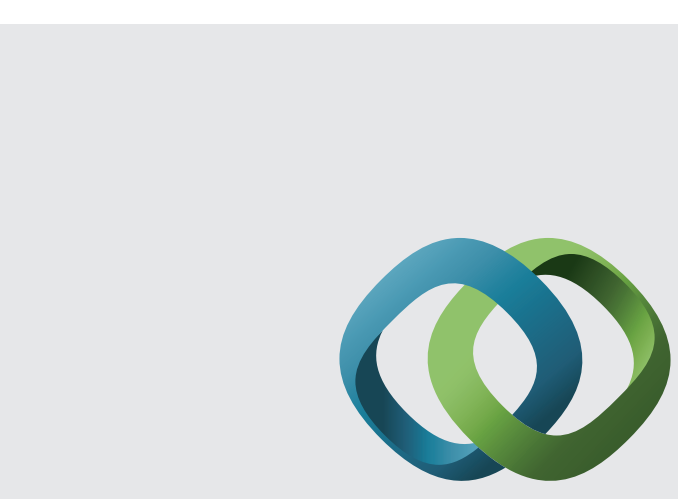

\section{Hindawi}

Submit your manuscripts at

http://www.hindawi.com
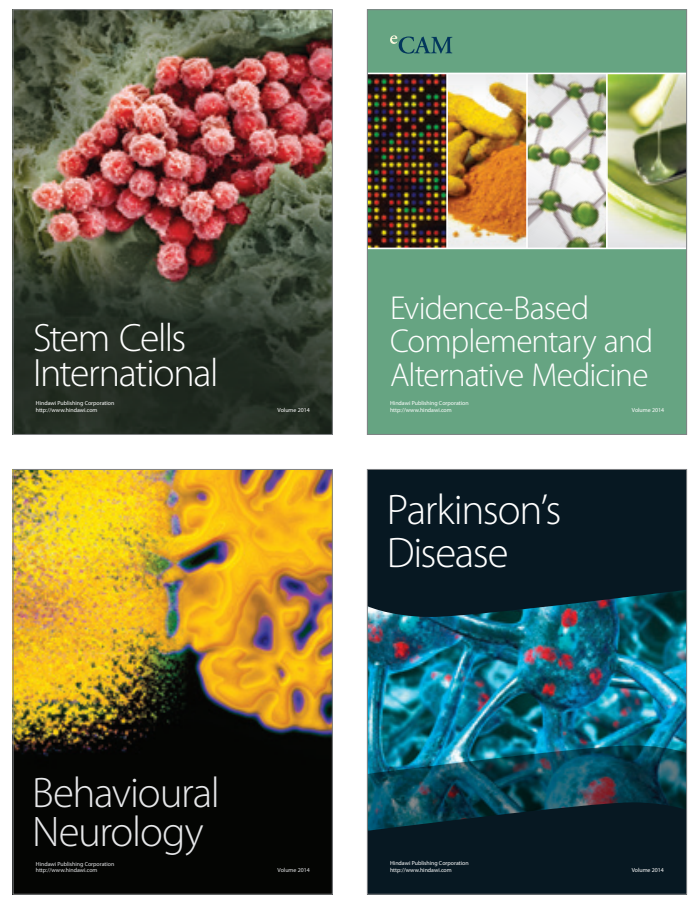
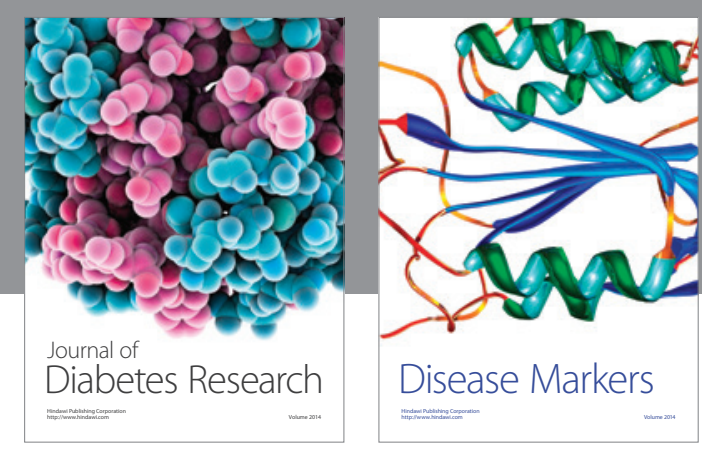

Disease Markers
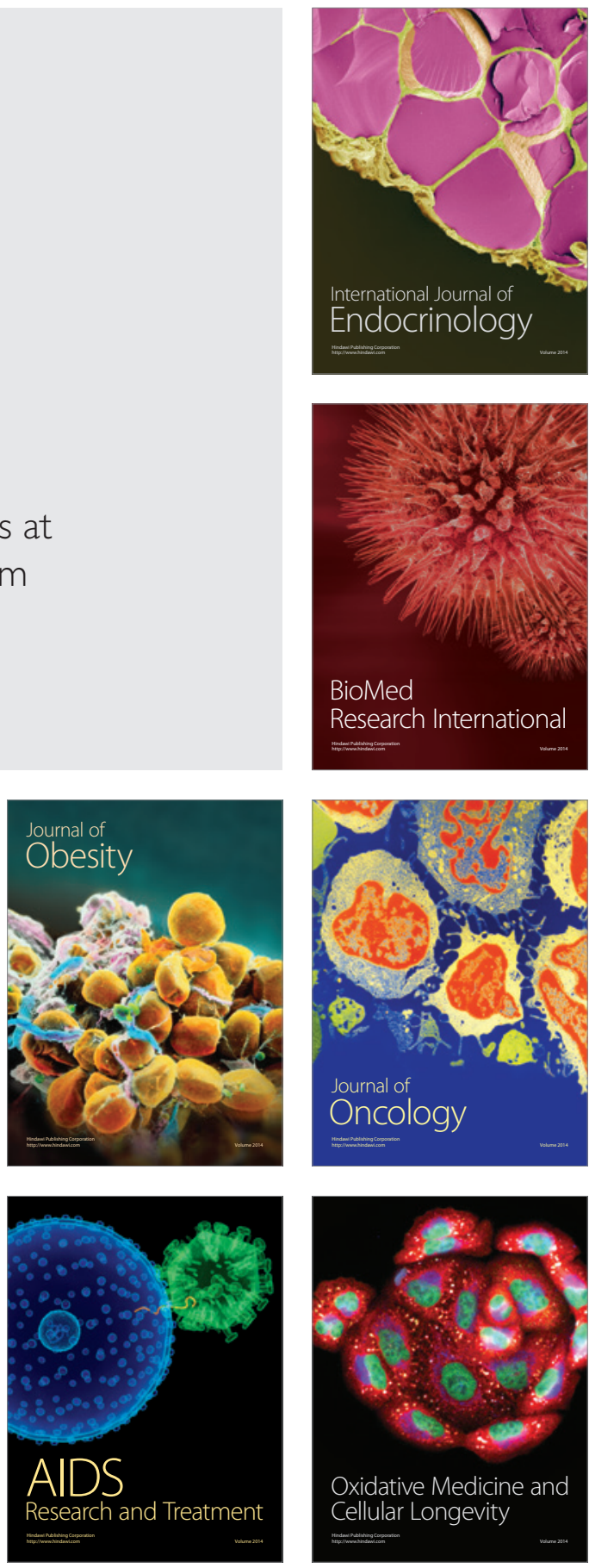